\title{
MIDAS
}

Museus e estudos interdisciplinares

$3 \mid 2014$

Varia e dossier temático: "Museos y participación biográfica"

\section{O Carnaval é um Palco, A Ilha uma Festa: Da performance cultural à exposição da sua metaperformance videográfica}

The Carnival Is A Stage, The Island A Feast: From cultural performance to the exhibition of its video metaperformance

\section{Rui Mourão}

\section{OpenEdition}

\section{Journals}

Edição electrónica

URL: http://journals.openedition.org/midas/582

DOI: $10.4000 /$ midas.582

ISSN: 2182-9543

\section{Editora:}

Alice Semedo, Paulo Simões Rodrigues, Pedro Casaleiro, Raquel Henriques da Silva, Ana Carvalho

\section{Refêrencia eletrónica}

Rui Mourão, « O Carnaval é um Palco, A Ilha uma Festa: Da performance cultural à exposição da sua metaperformance videográfica », MIDAS [Online], 3 | 2014, posto online no dia 03 novembro 2015, consultado no dia 04 maio 2019. URL : http://journals.openedition.org/midas/582 ; DOI : 10.4000/ midas.582

Este documento foi criado de forma automática no dia 4 Maio 2019.

\section{c) (1)}

Midas is licensed under a Creative Commons Attribution-NonCommercial-ShareAlike 3.0 International License 


\title{
O Carnaval é um Palco, A Ilha uma Festa: Da performance cultural à exposição da sua metaperformance videográfica
}

\author{
The Carnival Is A Stage, The Island A Feast: From cultural performance to the \\ exhibition of its video metaperformance
}

\section{Rui Mourão}

\section{Introdução}

1 Ao longo deste artigo apresentarei um enquadramento teórico em prol do recurso a métodos visuais na interpretação antropológica de elementos culturais intangíveis, dando um especial enfoque a abordagens videográficas, na sua metodologia tanto artística, como documental, para posterior exposição.

2 O objetivo é cruzar a antropologia visual com as estratégias e as práticas da arte contemporânea e, em particular, do vídeo e da instalação, tomando como caso de estudo a exposição 0 Carnaval é um Palco, A Ilha uma Festa, que esteve patente no Museu Nacional de Etnologia (Lisboa, 2012), assim como no Museu de Angra do Heroísmo (Ilha Terceira, 2012-2013) e no Espaço do Conhecimento - Museu da Universidade Federal de Minas Gerais (Belo Horizonte, Brasil, 2014). Para melhor compreensão desse projeto far-se-á uma breve descrição etnográfica do seu objeto de interesse, as danças de Carnaval da ilha Terceira, de modo a explicar as vantagens e as mais-valias de uma abordagem interpretativa em videoinstalação multicanal.

3 Embora ao longo deste excurso se apresente uma determinada metodologia interpretativa, não se pretende postular uma fórmula universal de exposição e musealização de património cultural imaterial. Pelo contrário, o que se busca com esta 
proposta é contribuir para uma maior e mais enriquecedora pluralidade de interpretações, sem invalidar o interesse das performatividades que as musealizações clássicas e as suas coleções permitem. Contudo, penso que essas inerentes fetichizações objetuais acompanhadas de remissivas narrativas textuais, só representam uma parte do fenómeno, o que pode ser limitativo para a compreensão de uma forma cultural imaterial ancorada em práticas e energias intersubjetivas. Daí a necessidade de apresentar uma experiência que possa abrir mais o campo a outras alternativas. Nesse sentido, seguir-se-á uma argumentada interpretação, com recurso a alguma bibliografia e de acordo com a minha práxis de artista visual a trabalhar com conteúdos e metodologias antropológicas, com vista a contribuir para a discussão sobre os dispositivos de representação de formas intangíveis de expressão cultural, para além da hegemónica normatividade da exposição de objetos materiais para expressar práticas imateriais.

\section{O património cultural imaterial como performance e a sua exposição como metaperformance}

What do performers and anthropologists have in common? As you may have guessed, it is their role as interpreters. Anthropologists are the interpreters of the cultures in which they work; they translate for a world unfamiliar with those cultures their coherence, distinctiveness, excitement. They are the medium through which one culture is "performed" for another. (Royce 1987, 3)

4 Todo o museu é um intérprete - um intérprete cultural - e a sua encenada leitura é particularmente evidente quando estamos diante de domínios imateriais, como sejam o teatro, a música, a ciência ou a etnografia. Tomemos como exemplo esta última disciplina para constatarmos que por mais imparcial, científica e racional que uma exposição etnográfica procure ser, é sempre o resultado de um labor de interpretação antropológica e, portanto, a um nível intelectual, emotivo e comunicativo, de certa forma, também obedece a um trabalho performativo, como aponta Royce (1987). Esta abordagem enquadra-se nos chamados estudos da performance que abordam o campo expandido da performance enquanto conceito já não só aplicado ao palco, ao museu, à galeria de arte e às atividades ditas artísticas, mas de forma multidisciplinar a todas as relações humanas.

For many of us performance has evolved into ways of comprehending how human beings fundamentally make culture, affect power, and reinvent their ways of being in the world. The insistence of performance as a way of creation and being as opposed to the long held notion of performance as entertainment has brought fourth a movement to seek and articulate the phenomenon of performance in its multiple manifestations and imaginings. (...) when we understand performance beyond theatrics and recognize it as fundamental and inherent to life and culture we are confronted with the ambiguities of different spaces and places that are foreign, contentious, and often under siege. (Madison e Hamera 2006, XII)

Conceptualizam-se, assim, os processos socioculturais como um constante desempenho performativo, no qual toda e qualquer ação intersubjetiva possui uma «poiesis cultural» (Madison e Hamera 2006, 46). Tal opera-se inclusivamente ao nível da produção interpretativa museológica e da interpretação intelectual nas ciências sociais. Interessame neste artigo abordar a questão no âmbito antropológico por tratar do património cultural imaterial na sua articulação do terreno etnográfico estudado para o posterior espaço expositivo com base num exercício de representação da «alteridade do Outro» (Madison e Hamera 2006, XV). Obviamente que esse exercício académico-museológico está muito dependente do conhecimento das normas dramatúrgicas da disciplina e do 
talento interpretativo dos seus atores, assim como da sua eloquência formal na apresentação. Por sua vez, a aceitação desses exercícios performativos varia em cada época de acordo com os públicos das vigentes elites político-intelectuais e com as suas práticas institucionais. É fundamental não perder a consciência, como Said tão incisivamente argumentou, que a representação da alteridade nas instituições de transmissão do saber são espaços onde o poder se exerce com profundas consequências (cit. por Conquergood 1989, 84).

O olhar objetivizante e examinador, que decompõe analiticamente, que controla e penetra tudo, adquire para as instituições uma força estruturante. É o olhar do sujeito racional, o qual perdeu todo o contacto puramente intuitivo com o seu meio e destruiu todas as pontes de comunicação intersubjetiva para a qual, no seu isolamento monológico, os outros sujeitos já só são acessíveis como objetos de observação passiva. (...) Essa mesma estrutura encontra-se nas ciências humanas. (...) Em primeiro lugar a Psicologia clínica, mas também a Pedagogia, a Sociologia, a Politologia, a Antropologia cultural podem ser incluídas sem qualquer problema (...). (Habermas 2010, 241-242)

Ora, tendo em conta esta já clássica crítica pós-moderna e partindo do princípio que a construção do conhecimento antropológico, tal como o de todas as ciências sociais e, de certa forma, também o das ciências naturais, é sempre algo interpretativo e, portanto, criativo. Não obstante, defendo o esforço de, ainda assim, se ser o mais objetivo possível quando toca à análise lógica para não cair no total relativismo desligado do real, uma maior integração expositiva entre uma dimensão mais racional e uma outra forma de comunicação e de conhecimento mais emocional. De acordo com o meu próprio percurso ligado às artes visuais, assumi e enveredei em pleno por essa interpretação criativa ao recorrer a métodos expositivos menos tradicionais. O Carnaval é um Palco, A Ilha uma Festa, consiste numa videoinstalação multicanal com imagens por mim recolhidas das danças de Carnaval da ilha Terceira, que foi apresentado primeiramente no Museu Nacional de 
Etnologia, de seguida no Museu de Angra do Heroísmo e mais tarde no Espaço do Conhecimento - Museu da Universidade Federal da Minas Gerais, no Brasil.

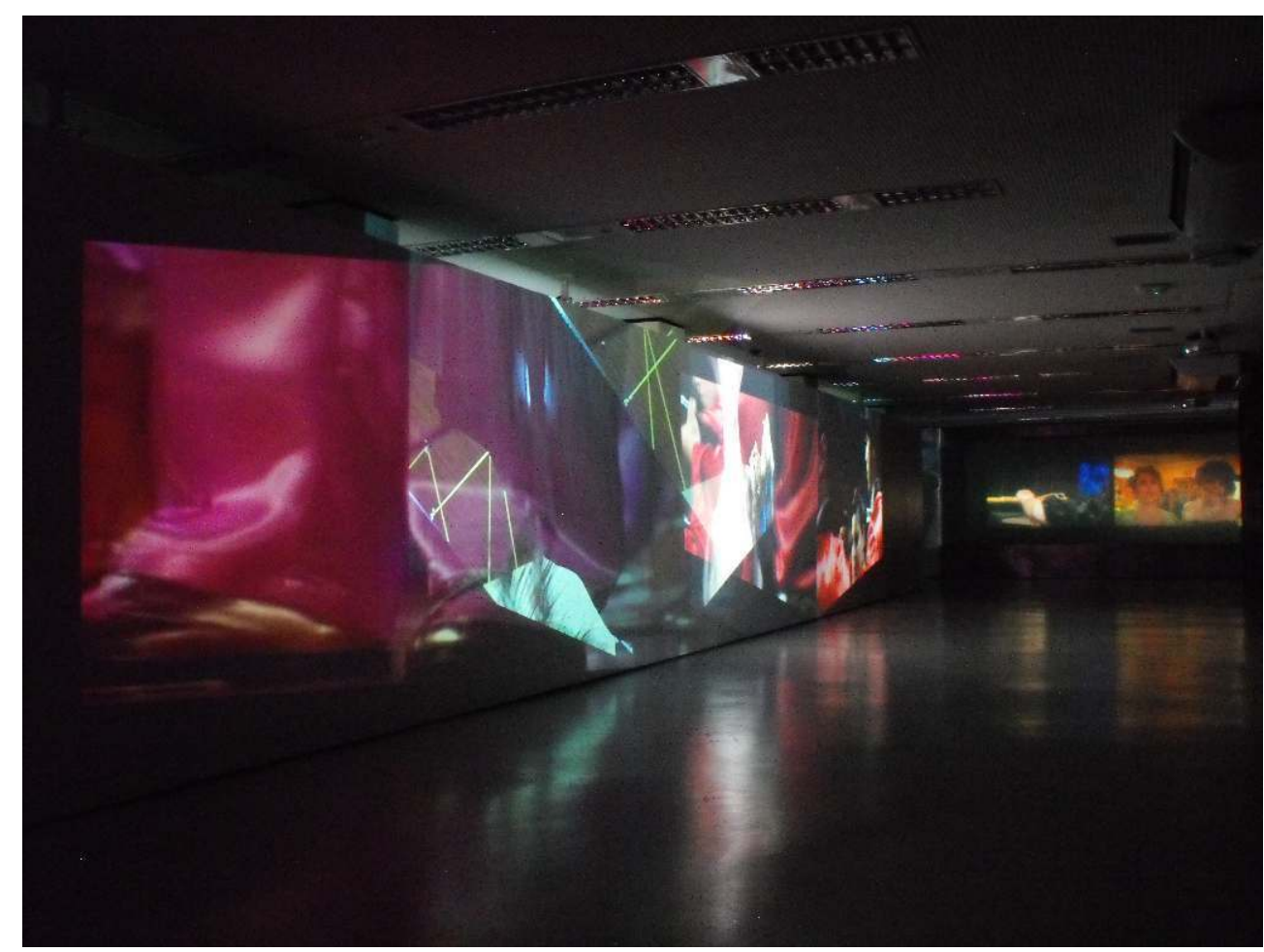

Fig. 1 - Vista da exposição O Carnaval é um Palco, A Ilha uma Festa, no Espaço do Conhecimento Museu da Universidade Federal de Minas Gerais, Belo Horizonte, Brasil, 2014

(c) RUI MOURÃo

7 Uma vez que as emoções constituem a base de referência biológico-mental para a atividade do resto do cérebro e da cognição (Damásio 2013, 213), privilegiou-se uma dimensão mais emocional e sensorial com a videoinstalação, sem nunca perder a lógica de análise ao fenómeno e sem pretender uma apresentação meramente onírica, de fuga à realidade. Pelo contrário, a instalação estava ancorada nas imagens deixadas pelas reais situações documentadas através do vídeo. Deste modo, desenvolveu-se todo um exercício de «metaperformance»" (Conquergood 1989, 86), enquanto mise en abyme da apresentação da minha interpretação a partir das interpretações de diferentes atores: os participantes nas festas das danças de Carnaval da Terceira. Tive, contudo, uma grande preocupação na procura de uma práxis séria de tradução conceptual que permitisse não cair num mero exercício narcísico que revelasse mais do autor interpretativo do que do objeto interpretado. De acordo com esse pressuposto, se a objetiva imparcialidade é um mito e o autor da exposição, curador ou artista, não se pode obliterar, sendo preferível assumir honestamente o seu posicionamento, o objeto antropológico também não pode deixar de ser o centro da questão. Por isso, embora haja sempre a tal dimensão performativa, emocional e criativa da interpretação inerente à prática antropológica, julgo ser importante o rigor e a ética na apresentação do património cultural imaterial e dos seus agentes, de maneira a centrar a análise no que se representa e não em quem o representa.

Perante estas estratégias metaperformativas de exposição do património cultural imaterial coloca-se a questão de estarmos diante de arte que se afirma antropologia ou de antropologia que se constitui arte? Mais importante que dar resposta a questões de 
precedências formais, ao delinear artificiais fronteiras normativas ou, pelo contrário, constatando uma inerente interdisciplinaridade, é perceber o valor simbólico (HooperGreenhill 1994, 203) dos fenómenos abordados. Perceber o que significam e transmiti-los segundo uma interpretação tão sensível, quanto documental.

\title{
A videoinstalação como dispositivo eficaz na apresentação museológica de formas imateriais de expressão cultural
}

\begin{abstract}
It is a matter of changes in professional and institutional practices, as much as retheorizing. Theoretical destabilization, or blurring of boundaries, is not an end in itself, and visual anthropology needs to be remade as a zone of practical potentials, of new methodologies, artefacts and knowledges. The focus should be on the potentials of representational practice, rather than on strict definitions of either anthropology or art. (...) One of the more pertinent points Rethinking Visual Anthropology raises for me is relegated to a small foot-note: "Sadly few anthropologists have yet tried to effect other-cultural representations primarily through artistic representation." (p. 32, n. 6) Although I disagree with the radical separation, opposition and reification of "art" and "anthropology", I hope that anthropologists do now begin to explore some of the potentials that this "third subject" holds. (Wright 1998, 21-22)
\end{abstract}

9 Em total concordância com o pensamento de Wright (1998), parece-me muito redutor analisar e expor formas imateriais de expressão cultural sem recorrer a uma antropologia visual que, na sua apresentação dos fenómenos abordados ao público, se exima de recorrer a um conjunto de imagens em movimento e correspondentes sons, numa relação holística. Pela sua intangibilidade e efemeridade não é possível ter as imateriais formas de expressão cultural dentro do museu, a não ser com uma temporária e menorizada reconstituição dramatizada em descontextualizada prática encenada e há certas formas imateriais de expressão cultural em que tal nem sequer é possível de dramatizar ao vivo no museu. Tão pouco me parece muito eficaz transmitir o património cultural imaterial apenas expondo os objetos ligados à práxis constitutiva desse património acompanhados de textuais descrições etnográficas. Já os media visuais permitem uma outra compreensão mais próxima do incorpóreo objeto a musealizar. Não através de métodos descritivos, mas de métodos de entendimento (MacDougall 1999, 286). Sobretudo se tivermos em conta que o foco de interesse está em ações performativas, portanto realizadas a partir de práticas do corpo e da relação cultural intersubjetiva, em que cada uma tem uma energia própria; sendo fundamental para o seu entendimento ver as relações interpessoais a ser operadas nas formas e contextos onde se praticam, nomeadamente ao nível das localizações, dos movimentos, dos sons, das expressões faciais ou corporais dos seus atores. Destacaria, pois, o recurso à videoinstalação pela possibilidade de visualização inter-relacional e de perceção holística dessas múltiplas expressões performativas nas suas reais e diversas práticas, energias, sentidos e espaços de ação.

Gil, no seu texto para a Bienal LisboaPhoto 2005, dava uma visão das imagens como registos imateriais do real saídos de uma caixa negra onde se encontra gravado determinado percurso, onde «cada elemento desprende-se dos outros e do conjunto, revelando a composição plural de imagens de que o real é feito. (...) e acabam mesmo por se ligar porque uma força as retém» $(2005,49)$. Nesse mesmo sentido, parece-me pertinente usar uma outra analogia à qual o autor também foi beber, inicialmente dada 
por Deleuze, e que igualmente considero bastante ilustrativa do conceito inerente à videoinstalação: a de uma «imagem-cristal» (Ibid.). Mas não uma imagem-cristal no mero sentido dicotómico que «não para de trocar a imagem atual do presente que passa e a imagem virtual do passado que se conserva» (Fornazari 2010, 9). No caso de um dispositivo videográfico multicanal, revela-se uma imagem-cristal não só na sua dimensão temporal, tal como teoriza Deleuze a partir das clássicas imagens monocanais do tipo fotográfico e cinematográfico, mas de forma mais complexa, em dimensões pluriespaciais e pluritemporais, a partir da exibição sobreposta de imagens, no caso antropológico preferencialmente imagens documentais, sobre o fenómeno observado em vários planos. São planos charneira, nos quais se conjugam diferentes espaços da ação retratados num único espaço de visualização e em diferentes tempos da ação num só momento apresentado no presente ao espectador que a visualiza. Tudo justaposto numa só apresentação holística, numa só instalação com várias imagens em movimento que, a partir da sua projeção multipolar, intersetada e rizomática, se relacionam umas com as outras como um todo.

11 O facto de uma videoinstalação de cariz artístico-etnográfico apresentar diferidamente formas imateriais de cultura, permite ainda a sua exposição no museu de forma repetida e recorrente, convertendo o efémero numa tipologia mais permanente e de fácil e económica conservação, arquivo, reinstalação e cedência para outras exposições externas à instituição. Indo mais longe, sendo o vídeo um património imaterial digital, o museu pode até disponibilizar a consulta desse acervo imagético via internet, por exemplo numa versão em linha da videoinstalação em formato korsakow ${ }^{3}$, alargando a sua ação a formas desmaterializadas que permitiriam chegar a públicos mais amplos, potencialmente à escala global. O grande valor específico da videoinstalação, com as suas inerentes estratégias, metodologias e formas de apresentação provenientes da arte contemporânea, é possibilitar que as imagens em movimento dos corpos e das suas práxis culturais, sejam expostas quer em planos individuais específicos, quer coletivamente num todo multicanal, como um cenográfico e coreográfico conjunto, envolvendo o recetor em sensoriais processos heurísticos criadores de sentidos diversos.

[...] viver uma emoção não é nenhuma misteriosa qualidade mental, mas sim, em grande parte, o resultado da perceção direta de uma paisagem específica: a do corpo. (...) Dado que o impacto dessa paisagem exterior se justapõe, com o tempo, à perceção ou à lembrança de outras coisas que não fazem parte do corpo - um rosto, uma melodia, um aroma - as emoções acabam por se transformar em "qualificadores" dessa outra coisa. (...) Funcionam como guias internos e ajudamnos a transmitir aos outros certos sinais que também podem guiar os seus comportamentos. (...) É o resultado de uma curiosa conciliação fisiológica com a qual o cérebro se transformou num público atento, obrigatório, prisioneiro mesmo, das atividades teatrais do corpo. (Damásio 2013, 18-20)

12 A apreensão das coisas pelo homem faz-se através dos sentidos, pelo que, como os meios de comunicação e a publicidade sabem muito bem, a comunicação através da imagem, e das emoções que estas imprimem ao olhar, à audição, ao corpo, à mente, chega de forma muito mais eficaz, impactante e duradoura junto do recetor, do que uma mera comunicação textual ancorada em objetos remissivos de pretéritas ações intangíveis, como acontece nas clássicas musealizações etnográficas. Com esta argumentação não defendo que se excluam essas formas mais clássicas de exposição do património cultural imaterial, pelo valor único dos objetos e do texto, mas sim que se complementem de forma mais intensa com uma abordagem videográfica, sobretudo de videoinstalação. 
13 Resumindo, é fundamental o recurso a materiais visuais para registar, analisar e representar tudo o que diz respeito a elementos culturais também eles visuais (Wright 1998, 16), em particular quando se trata de uma linguagem não-verbal, como emoções, expressões, atitudes ou práticas, nas suas manifestações individuais e coletivas (Pasqualino 2007, 84). Tanto ao nível dos processos de pesquisa antropológica, como da sua interpretação, apresentação, exposição e musealização.

Here it is necessary to insist that visual anthropology is not about the visual per se but about a range of culturally inflected relationships enmeshed and encoded in the visual. Just as anthropology can read some of these in the visual, so too it can use the visual to construct works that give a richer sense of how culture permeates and patterns social experience. These works may bring into play familiar ways of engaging with visual media, such as realist strategies of narrative, identification and description, or less familiar forms of juxtaposition and montage that address the viewer on multiple levels. (MacDougall 1999, 288)

Indo ao encontro das posições defendidas por MacDougall (1999), Banks e Morphy (1999) ou Wright (1998), de procurar levar a antropologia visual a repensar as suas estratégias de representação e ligação com o mundo (Wright 1998, 16), sem se reduzir a simples ilustração da dimensão escrita (Pasqualino 2007, 84), o conceito subjacente à opção de mostrar os resultados de pesquisas visuais na forma de videoinstalação multicanal prende-se com a ideia de representar coreografias de corpos em ações antropológicas, a partir de imagens documentais. Cada imagem se liga a outra e, simultaneamente ao conjunto, constituindo uma composição plural a partir de várias projeções. Esse todo, reflete virtualmente várias realidades performadas e funciona como analogia do evento. Isto é particularmente pertinente para eventos ligados à dimensão da festa, como passaremos a tratar de seguida.

\section{Um estudo de caso: As Danças de Carnaval da Terceira e a sua representação na exposição 0 Carnaval é um Palco, A llha uma Festa}

Como já antes argumentei, vejo a antropologia e a sua encenação museológica como uma forma de conhecimento e de comunicação produzida com base na interpretação, pelo que na sua criação há uma dimensão artística. Em sentido inverso, eu próprio tenho vindo a criar trabalho artístico com uma metodologia apropriada de certas práticas de investigação antropológica, optando frequentemente por um registo videográfico documental do real que depois reinterpreto, por via da edição e apresentação contraposta das imagens.

Seguindo a minha práxis artística e no âmbito de uma pós-graduação em culturas visuais digitais no Instituto Superior de Ciências do Trabalho e da Empresa-Instituto Universitário de Lisboa (ISCTE), decidi trabalhar sobre as danças de Carnaval da Terceira, deslocando-me em fevereiro de 2012 à ilha para trabalho de investigação e documentação através do vídeo. Posteriormente, de 18 de maio a 1 de julho do mesmo ano o projeto foi exposto no Museu Nacional de Etnologia, em Lisboa. De 16 de novembro de 2012 a 12 de fevereiro de 2013, com o intuito de apresentar o resultado do projeto à comunidade terceirense, a exposição esteve patente no Museu de Angra do Heroísmo. As imagens foram ainda mostradas na Cinemateca Portuguesa-Museu do Cinema a 22 de fevereiro de 2013 e de 1 de março a 29 de maio de 2014, apresentou-se a videoinstalação no Espaço do 
Conhecimento - Museu da Universidade Federal de Minas Gerais, em Belo Horizonte (Brasil).

17 Para compreender a performance dessa exposição, é necessário fazer antes uma breve introdução sobre a manifestação cultural que a videoinstalação pretendeu representar.

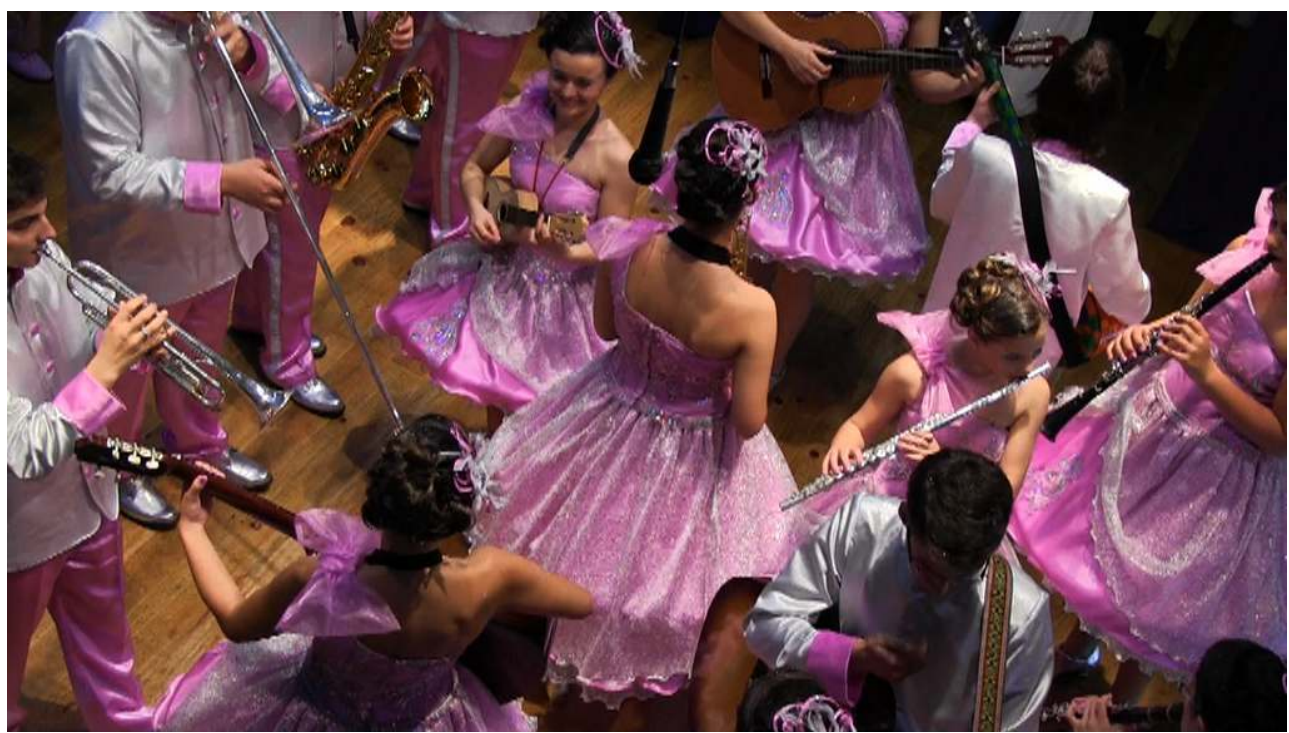

Fig. 2 - Video still de O Carnaval é um Palco, A Ilha uma Festa. 2012

(C) RUI MOURÃo

$\mathrm{Na}$ ilha Terceira, pela época do Entrudo, realiza-se um tipo de espetáculos populares, englobando teatro, dança e música, que se apresentam apenas nessa época. São as denominadas danças de Carnaval (Bretão 1998; Gomes e Costa 1999), que podem ser comédias (textos de sátira política e social), danças de espada (tragédias derivadas de antigos autos religiosos onde atualmente se representam dramas históricos e da vida atual da comunidade) ou bailinhos (de origem profana, são os mais comuns e apreciados pela população por serem mais feéricos e lúdicos, somando à sátira muita música; podem ser bailinhos de pandeiro ou de ferrinhos dependendo do estilo de música e dos instrumentos musicais envolvidos). Há algumas décadas atrás as danças de Carnaval faziam-se em terreiros, em casas particulares ou à porta das igrejas. Hoje em dia são apresentadas nos salões de teatro das sociedades recreativas e musicais, sendo inclusive transmitidas digitalmente por TV cabo para toda a ilha e via internet, em livestream, para a América, onde residem várias comunidades terceirenses.

19 Num reduzido espaço insular há dezenas de grupos teatrais: 57 grupos no Carnaval de 2012 e 65 no de 2013; o que se traduz em mais de 1000 ou 2000 espetáculos em apenas quatro dias, pois cada grupo faz em média cinco a dez atuações por noite. Os grupos vão nesses dias à volta da ilha apresentar as suas danças às freguesias rurais vizinhas. As invulgares características de um teatro popular sazonal, segundo a sua identidade insular afirmada numa performatividade carnavalesca, com amplo envolvimento social, faz deste um fenómeno cultural único a nível nacional e, provavelmente, a nível internacional, embora fora da região seja praticamente desconhecido. 


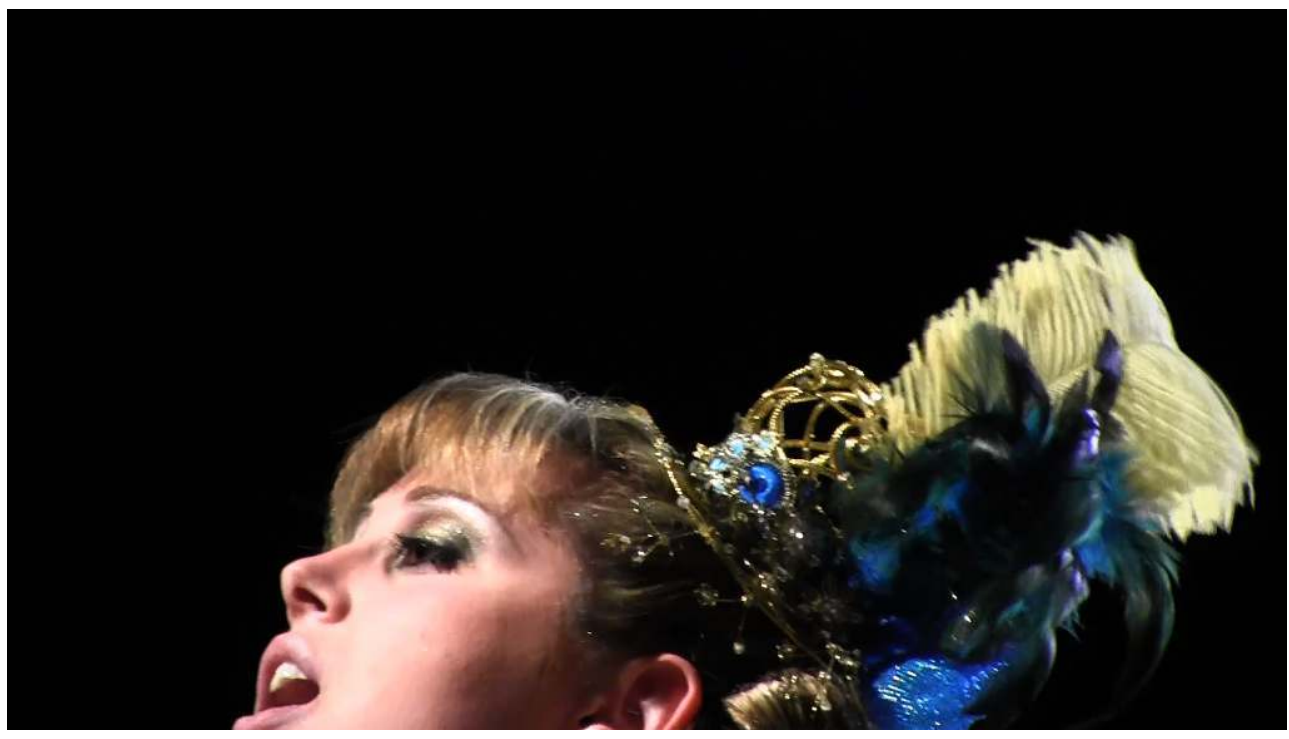

Fig. 3 - Video still de O Carnaval é um Palco, A Ilha uma Festa. 2012

(c) RUI MOURÃo

20 Há todo um ambiente de transfiguração coletiva, onde muitos, independentemente das suas profissões quotidianas, por uma breve altura do ano se tornam artistas, criando um folclórico teatro, secular e contemporâneo, de exuberantes trajes de cena e de importante dimensão musical interpretada por instrumentos tanto tradicionais (p. ex. cavaquinhos ou pandeiretas) como eruditos (p. ex. oboés ou clarinetes), a que se soma convivialidade, assumindo-se, deste modo, as práticas culturais como geradoras e intensificadoras de laços afetivos e de coesão social na comunidade.

Ao longo do meu trabalho na ilha preocupei-me em abordar diferentes aspetos que caracterizassem o espírito do Carnaval terceirense. Todo o processo se desenvolveu pensando numa montagem expositiva que apresentasse diferentes dimensões entrecruzadas, num dispositivo de vídeo multicanal, através do qual cada projeção mostrasse uma representação visual de sentidos que espelhasse uma múltipla perceção ao espectador de um fenómeno também ele múltiplo na sua estrutura artística, cultural, social, histórica, económica, política, etnográfica e, no fundo, identitária. ${ }^{4}$

Por um lado, procurei documentar em imagens o que corre o risco de desaparecer porque é frágil, efémero, imaterial, por outro lado, quis sublinhar o que é inovador, criativo, dinâmico. Na videoinstalação estas duas forças entrecruzavam-se, tal como na realidade.

As imagens, num recíproco contágio entre a antropologia visual e a videoarte, revelavam os participantes das danças em ação, quer enquanto artistas com estetizados planos dos passos de dança, das expressões de sátira ou de uma coreografia feita com espada antiga, quer enquanto atores sociais (viam-se grandes planos do convívio à mesa, planos gerais do público a rir ou travellings e panorâmicas ${ }^{5}$ dos jovens em digressão pela ilha). Era possível ver na exposição, ampliadas emoções expressas nos rostos dos espectadores, assim como a sofreguidão com que nos bastidores se mudava de roupa antes de cada entrada e, após a atuação, o ambiente à volta da mesa onde todos comiam juntos e chegavam a fazer rimas ao despique.

24 Ao nível de testemunhos, preocupei-me em falar com o máximo de pessoas possível, filmando várias entrevistas. Entrevistei especialmente terceirenses, não só participantes como profundos conhecedores do processo festivo e da história do Carnaval. Desde o 
taxista-dramaturgo Hélio Costa no gabinete onde escreve enredos ${ }^{6}$ para danças, passando pelo padre Francisco Dolores dissertando sobre o Carnaval entre a igreja e a sua biblioteca ou Marta Cardoso, a animada anfitriã do jantar de comadres, circulando pelos espaços sociais da festa. Em Lisboa, entrevistei académicos que deram um segundo olhar à visão interna e envolvida dos terceirenses com uma perspetiva especializada em teatro popular português: Guilherme Filipe, ator e professor, e em antropologia: Joaquim Pais de Brito, diretor do Museu Nacional de Etnologia, e Paulo Raposo, professor do ISCTE.

$\mathrm{Na}$ ilha, a certa altura, passei de entrevistador a entrevistado, tornando-me a meio do processo objeto de atenção da comunicação social local: fui entrevistado para a RTP Açores, para o Rádio Club de Angra e para o jornal A União, o que revela a importância do olhar de fora num pequeno meio isolado. A perspetiva exterior passou a ser desejada pela comunidade, que se queria ver ao espelho no olhar do outro. Há sempre uma influência da observação e interpretação vinda de fora na criação de uma identidade coletiva, particularmente numa condição insular. Por isso optei por incorporar na videoinstalação as entrevistas que me foram feitas pela comunicação social local. Ficaram como diálogo remanescente desse jogo de câmaras, no qual os profissionais da televisão local filmavam o artista-antropólogo que os veio observar enquanto o artista-antropólogo os filmava a eles, numa troca de olhares entre mútuos objetos e mútuos sujeitos.

$\mathrm{Na}$ videoinstalação, das duas projeções que exibiam as entrevistas, apenas uma era acompanhada de alto volume, estando o áudio da outra projeção disponível através de auscultadores a partir dos quais se acedia à análise antropológica e histórica do fenómeno pelos especialistas. Na sala de exposição era ainda possível ouvir-se os sons da vivência carnavalesca nas sociedades, mas para que tudo fosse percetível os sons tiveram de ser menos inter-relacionados no conjunto do que a instalação das imagens. Foi dado especial enfoque na montagem áudio à música e aos sons do público (p. ex. risos, palmas, convívio) que surgiam apenas de maneira intermitente e alternada, vindos de diferentes colunas em diferentes pontos do espaço.

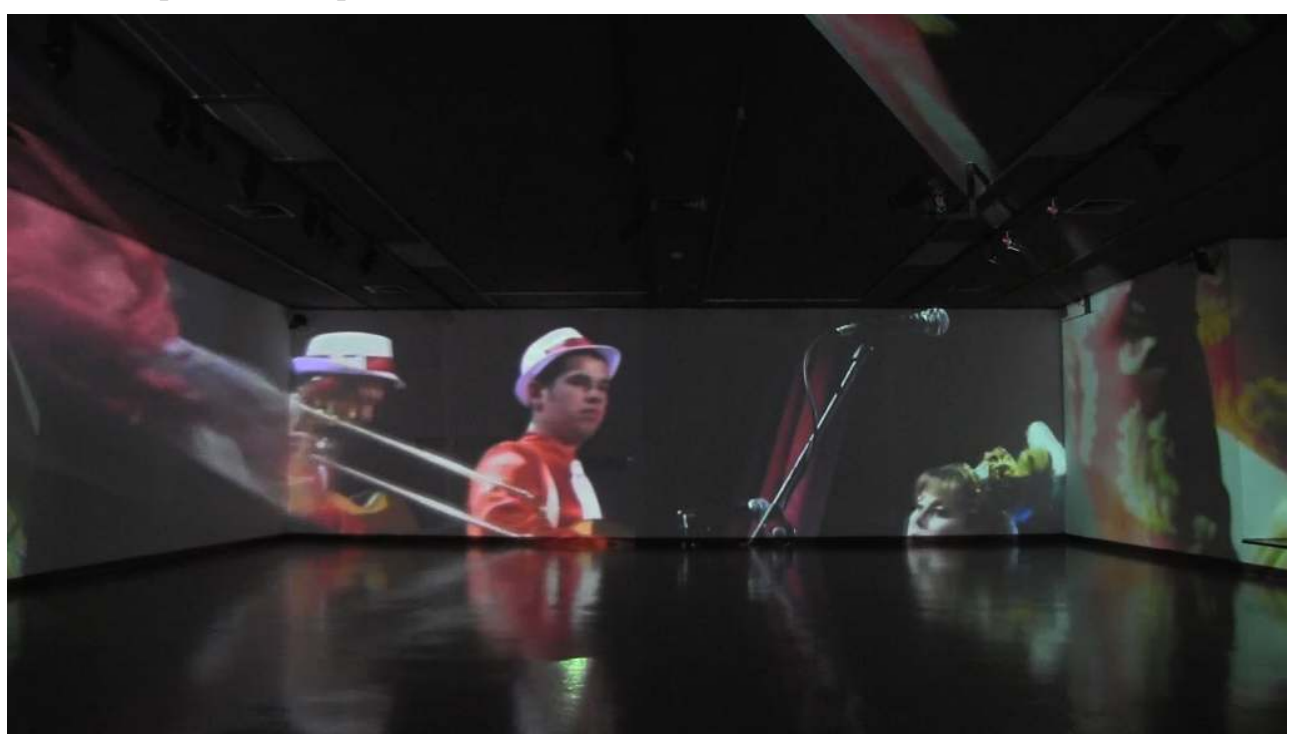

Fig. 4 - Vista da exposição O Carnaval é um Palco, A Ilha uma Festa, no Museu Nacional de Etnologia, Lisboa, 2012

(c) RUI MOURÃo

27 Detalhes de cenas performadas em palco foram projetadas em grande formato nas paredes do fundo da exposição. Na galeria de exposições temporárias do Museu Nacional 
de Etnologia havia quatro projeções desses detalhes de cena, no Espaço do Conhecimento havia cinco e na sala Dacosta do Museu de Angra do Heroísmo havia apenas duas, projetadas nos nichos de pedra da sala de exposições, que conserva os traços arquitetónicos do original convento, ganhando uma outra dimensão de apresentação mais do tipo site-specific. Em qualquer uma das exposições havia uma projeção só com a função de exibir as experiências e o ambiente de uma digressão de jovens pela ilha a apresentar o seu bailinho. Aí era possível ver também vários preparativos em torno da festa, como por exemplo ensaios, gastronomia, ateliê de confeção de trajes de cena, elaboração dos sofisticados penteados no cabeleireiro, pintura dos desenhos nas unhas, afinação dos instrumentos musicais. Além disso eram abordadas as questões de género e de identidade sexual nas danças de Carnaval, pela sua permitida experimentação transgénero, com uma tradicional prática de travestismo em palco, mas, simultânea e paradoxalmente, também de expressa homofobia. Nesta projeção mais longa, de mais de duas horas, exibia-se ainda um dos tradicionais jantares de mascarados.

Como metodologia de trabalho de campo, dos quatro dias de festa, fiquei dois numa única sociedade recreativa, na Terra Chã, focando-me mais nas atuações e no público a assistir, para depois na videoinstalação mostrar o ambiente geral numa sociedade. Nos outros dois dias acompanhei um grupo em digressão à volta da ilha com a Dança de Pandeiro da Terra Chã - Sociedade Filarmónica, pois faz parte da tradição, reforçada com os modernos meios de transporte, os grupos apresentarem as suas danças no maior número possível de freguesias da ilha. É um percurso que começa pelo fim da tarde e que só termina entre as 4 e as 6 horas da manhã. Fiz, assim, toda uma sequência de planos com câmara na mão e sem tripé, ao contrário de todos os outros, filmando com aceitação geral os jovens nas carrinhas em digressão. Documentou-se a sua viagem repleta de cantorias, com várias conversas e brincadeiras, espetáculos por eles realizados e por eles vistos e até os constantes foguetes lançados para a população a anunciar a nossa chegada a um salão. Ao som de um foguete todos sabem que cerca de 15 minutos depois começa uma dança, e todos estão atentos aos foguetes nesses dias porque, como dizia um dos participantes: Nunca se sabe quando chega um bailinho de outra freguesia ou o que traz.

Na noite da inauguração da exposição, o Museu Nacional de Etnologia esteve em direto, por videoconferência, via internet, em ligação com a Sociedade Recreativa e Musical da Terra Chã. As imagens da ligação Skype foram projetadas numa parede do espaço expositivo. Pretendia-se, assim, um envolvimento da comunidade da localidade terceirense à representação do seu património cultural imaterial exposto em Lisboa. Simultaneamente, dava-se uma oportunidade às pessoas na exposição de poderem colocar perguntas sobre as imagens expostas aos seus verdadeiros protagonistas. Por uns momentos foi possível ao visitante da exposição travar conhecimento com alguns dos atores daquelas tradições, nomeadamente num dos principais cenários onde decorreram as filmagens e, portanto, onde aconteceu a festa popular objeto de estudo e de imagética patrimonialização. Para as pessoas na Terra Chã foi uma forma de, apesar da distância, estarem presentes na inauguração de um evento no qual eram o centro das atenções, ao convocá-los e envolvê-los na exposição, onde mais do que o objeto foram colaboradores participantes. Esses mesmos colaboradores estiveram, mais tarde, fisicamente presentes na inauguração da exposição na sua ilha, no Museu de Angra do Heroísmo, onde também eles se puderam ver representados nos vídeos, ou seja, onde viram as suas práticas culturais musealizadas. Inclusive, a videoinstalação passou a fazer parte da coleção do Museu de Angra do Heroísmo. 


\section{Conclusão}

Face ao enunciado, concluiu-se que a opção pela videoinstalação permitiu uma montagem expositiva constitutiva de uma outra perspetiva museológica que gerou um conhecimento disciplinar diferente daquele que se obtêm com as práticas mais convencionais; além de promover uma experiência mais intensa de entendimento sensorial pelo visitante do museu. Essas experiências são particularmente importantes na transmissão do valor simbólico de fenómenos ligados a formas imateriais de expressão cultural e, em particular, de práticas da performance e da festa.

31 No caso referencial deste artigo, a exposição O Carnaval é um Palco, A Ilha uma Festa teria ficado muito mais pobre se não se pudessem visualizar todos os eventos referidos: os locais onde ocorreram, os seus participantes, as suas ações, as relações e as performances, tanto artísticas no palco, como fora dele, a um nível sociocultural.

O objetivo foi tirar partido do medium videográfico para expor o que nenhum texto, relato oral, fotografia, mapa, traje ou objeto usado nas danças de Carnaval poderia mostrar, por exemplo: a criança que adormece a ver o espetáculo, o brilho nos olhos dos mais velhos, as coletivas gargalhadas na plateia e tudo o que se revela demonstrativo do espírito, das relações e da energia aí vividos. A partir desses elementos audiovisuais foi possível criar uma multifacetada imagem-cristal, na qual a ação dos diferentes participantes se interligava em várias projeções (13 no Espaço do Conhecimento e oito no Museu Nacional de Etnologia e no Museu de Angra do Heroísmo), criando um espaço concentrado de imagética encenação expositiva que recriou de forma concentrada todo o fenómeno.

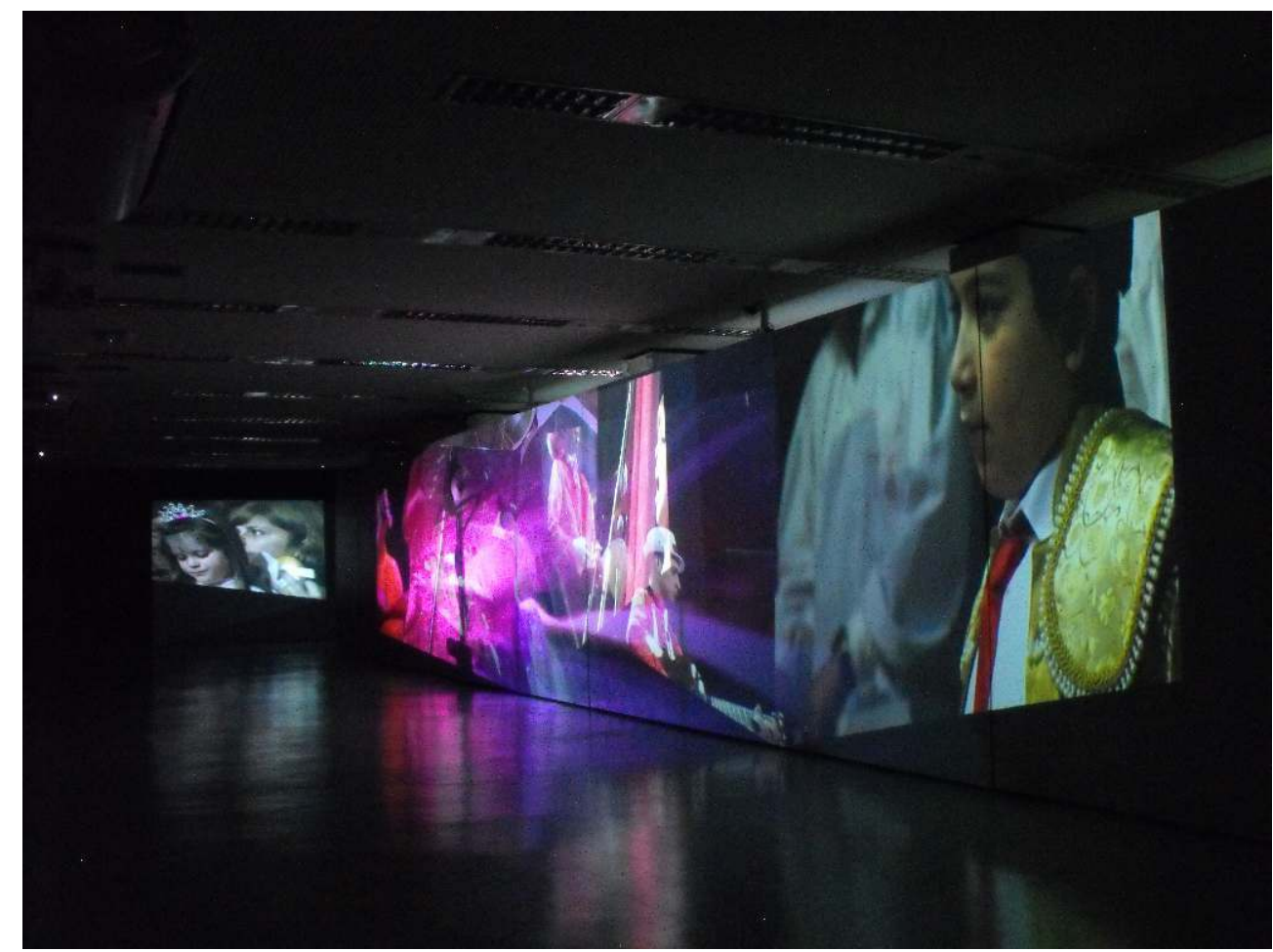

Fig. 5 - Vista da exposição o Carnaval é um Palco, A Ilha uma Festa, no Espaço do Conhecimento Museu da Universidade Federal de Minas Gerais, Belo Horizonte, Brasil, 2014

(C) RUI MOURÃO 
Optei por interpretar um património intangível artístico, sob uma perspetiva igualmente artística, visando uma eficaz coerência qualitativa, um documentalismo mais criativo e uma melhor compreensão pela via visual das performatividades culturais imateriais. 0 desafio foi tornar isso numa mais-valia para a exposição, apresentando uma sedutora e sensorial concretização menos convencional, com objetivos, processos e respostas alternativos aos paradigmas hegemónicos da museologia das coisas imateriais; o que só per se ajuda ao exercício de uma maior pluralidade de representações museográficas, que é sempre enriquecedora para o conhecimento e para a experiência de diferentes públicos.

Tal como o objeto de imaterial interesse patrimonial, assim o resultado final, na sua dupla construção de análise antropológica e de objeto artístico, inevitavelmente refletiu algo de mim, acompanhado de uma consciência de não se constituir como mero retrato de artista, pretendendo uma verdadeira intersubjetidade com a comunidade.

No que diz respeito ao público da exposição, um dos comentários mais frequentes foi a sensação de partilha de toda aquela feérica emotividade e alegria vividas na festa, através da envolvente audiovisual. Em grande parte sentiam que tal lhes chegava por via de uma dinâmica panóplia de cores, movimentos e sons festivos dados pelas multipolares imagens em movimento à sua volta. Mas, muito em particular, sentiram essa partilha nos constantes grandes planos de expressões dos participantes das danças: quer ao nível do enfoque em expressões faciais e corporais do público a assistir em comunhão coletiva no teatro e à volta da mesa; quer ao nível das expressões sentimentais dos atores nas suas interpretações no palco, que em imagens fragmentadas, remontadas e muitas vezes desvinculadas do som e isoladas do resto da ação, ganhavam uma maior presença, uma força própria. A tal força própria, reveladora da energia motivadora, sentimento matriz, que os participantes da festa, ao se reverem posteriormente nas imagens, identificaram como sendo o elemento não palpável mobilizador de tanto trabalho, tempo, energia e dinheiro investido.

Acrescente-se que me foi transmitido, direta e indiretamente, por vários terceirenses, que o facto de levar o espírito e a imagem das danças de Carnaval da Terceira para o interior de um museu e, especialmente, para um prestigiado museu nacional, o Museu Nacional de Etnologia, e no contexto internacional para o Espaço do Conhecimento, ligado à Universidade Federal de Minas Gerais, no Brasil, por si só deixou os participantes deste fenómeno cultural, em geral, muito satisfeitos. Creio que tal se deve a uma perceção da comunidade local de subvalorização, ou mesmo desconhecimento, da sua cultura e tradições fora da ilha. Como tal, sentiram um certo empoderamento identitário no reconhecimento e visibilidade da importância das suas manifestações culturais, contribuindo para estimular sentimentos de autoestima coletiva e de pertença comunitária. Em parte, por causa disso, a realização deste projeto teve uma tão significativa cobertura mediática local. É de notar que as danças de Carnaval são uma tradição de origem popular e rural, tendo sido conotadas como baixa cultura pelas elites de Angra do Heroísmo durante décadas, talvez séculos, embora sejam cada vez mais aceites e alvo da curiosidade das populações urbanas/semiurbanas locais. Nesse sentido, o próprio ato museológico ganhou dimensão política ao levar em 2012-2013 estas manifestações tradicionalmente associadas à baixa cultura para o interior da instituição cultural mais prestigiada da ilha, o Museu de Angra do Heroísmo, agente relevante na definição e legitimação do que localmente é património cultural valorizado. 
Finalmente, não se pode deixar de sublinhar que o acolhimento deste projeto expositivo nas programações do Museu Nacional de Etnologia e do Museu de Angra do Heroísmo constata o caminho de aceitação que os dispositivos de imagem em movimento, enquanto intérpretes de uma antropologia visual, já fizeram no meio museológico português.

\section{BIBLIOGRAFIA}

Anico, Marta. 2008. Museus e Pós-modernidade: Discursos e "Performances" em Contextos Museológicos Locais. Lisboa: Instituto Superior de Ciências Sociais e Políticas e Universidade Técnica de Lisboa.

Banks, Marcus, e Howard Morphy, eds. 1999. Rethinking Visual Anthropology. New Haven: Yale University Press.

Borba, Liduíno. 2013. Alcindo, o Profeta do Carnaval. Angra do Heroísmo: Turiscon Editora.

Branco, Jorge Freitas. 2008. "Significados Esgotados: Sobre Museus e Coleções Etnográficas.” In El Futuro de los Museos Etnológicos: Consideraciones Introductorias para un Debate, coordenado por Xavier Roigé I Ventura, Esther Fernández de Paz, e Iñaki Arrieta Urtizberea, 53-68. San Sebastián: Ankulegi Antropologia Elkartea. http://www.euskomedia.org/PDFAnlt/antropologia/11/03/ 03053068.pdf.

Bretão, José Noronha. 1998. As Danças do Entrudo: Uma Festa do Povo, Teatro Popular da Ilha Terceira. 2 vols. Angra do Heroísmo: Direção Regional da Cultura.

Carvalho, Ana. 2011. Os Museus e o Património Cultural Imaterial: Estratégias para o Desenvolvimento de Boas Práticas. Vol. 28. Biblioteca - Estudos \& Colóquios. Lisboa: Edições Colibri e Centro Interdisciplinar de História, Culturas e Sociedades da Universidade de Évora.

Conquergood, Dwight. 1989. "Poetics, Play, Process, and Power: The Performative Turn in Anthropology." Text and Performance Quarterly 9 (1): 82-95.

Damásio, António. 2013. O Erro de Descartes: Emoção, Razão e Cérebro Humano. 2. ${ }^{a}$ ed. Lisboa: Temas e Debates e Círculo de Leitores.

Fornazari, Sandro Kokol. 2010. "A Imagem-Cristal: A Leitura Deleuziana de Bergson nos Livros Sobre o Cinema." Artefilosofia (9): 93-100. http://www.raf.ifac.ufop.br/pdf/artefilosofia_n09/ Pag_93.pdf.

Foster, Hal. 1996. “The Artist as Ethnographer?” In The Return of the Real: The Avant-garde at the End of the Century, 302-308. Cambridge: The MIT Press.

Gil, José. 2005. “A Imagem Iminente.” In Bienal LisboaPhoto 2005, 45-53. Lisboa: Câmara Municipal de Lisboa - Pelouro da Cultura e Público - Comunicação Social S.A.

Gomes, Augusto, e Eduardo Ferraz da Costa. 1999. Danças de Entrudo nos Açores. Angra do Heroísmo: Edições Blu.

Goodey. Brian. 2005. “Interpretação e Comunidade Local.” In Interpretar o Património: Um Exercício do Olhar, organizado por Stela Maris Murta, e Celina Albano, 47-73. 1. reimpr. Belo Horizonte: Editora UFMG e Território Brasilis. 
Habermas, Jürgen. 2010. O Discurso Filosófico da Modernidade. Tradução de Ana Maria Bernardo. Alfragide: Texto Editores.

Hooper-Greenhill, Eilean. 1994. Museums and Their Visitors. London: Routledge.

Hooper-Greenhill, Eilean. 2007. Museums and Education: Purpose, Pedagogy, Performance. London: Routledge.

Leal, João. 2009. “O Património Imaterial e a Antropologia Portuguesa: Uma Perspetiva Histórica.” In Museus e Património Imaterial: Agentes, Fronteiras e Identidades, coordenado por Paulo Ferreira da Costa, 289-295. Lisboa: Instituto dos Museus e da Conservação.

Macdougall, David. 1999. “The Visual in Anthropology.” In Rethinking Visual Anthropology, editado por Marcus Banks, e Howard Morphy, 276-295. New Haven: Yale University Press.

Madison, D. Soyini, e Judith Hamera, eds. 2006. The Sage Handbook of Performance Studies. Thousand Oaks: Sage Publications.

Martin, Sylvia. 2006. Videoarte. Tradução de Josep Corbera. Colónia: Tashen.

Mourão, Rui. 2012. O Carnaval é um Palco, A Ilha uma Festa. Lisboa: Imprensa Municipal / Câmara Municipal de Lisboa. http://museu-angra.azores.gov.pt/eventos/2012/18-carnaval/ catalogo_ocarnavaleumpalco.pdf.

Pasqualino, Caterina. 2007. "Filming Emotion: The Place of Video in Anthropology." Visual Anthropology Review 23 (1): 84-91.

Royce, Anya Peterson. 1987. "Guest Editorial: The Anthropology of Performance and the Performance of Anthropology." http://www.oup.com/us/pdf/cultant/royce.pdf.

Said, Edward W. 1978. Orientalism. New York: Vintage Books.

Sancho Querol, Lorena. 2010. “Musealizando El Patrimonio Cultural Inmaterial.” In Atas do I Seminário de Investigação em Museologia dos Países de Língua Portuguesa e Espanhola, editado por Alice Semedo, e Elisa Noronha Nascimento, 1: 226-37. Porto: Universidade do Porto.

Schechner, Richard. 1981. "Performers and Spectators Transported and Transformed." The Kenion Review 3 (4): 83-113.

Schechner, Richard. 2003. Performance Theory. London e New York: Routledge.

Turner, Victor W. 1986. The Anthropology of Performance. New York: PAJ Publications.

Wright, Chris. 1998. "The Third Subject: Perspetives on Visual Anthropology." Anthropology Today 14 (4): 16-22.

\section{NOTAS}

1. Termo utilizado inicialmente por Turner. Ver a sua abordagem da «antropologia da performance» e da «cultura como performance» (1986).

2. Tal acontece, com frequência, em certo tipo de investigações colaborativas tão em voga no mundo da arte contemporânea, que geralmente são apreciadas por aliar a figura do artista com a de comunidades, mas que recorrentemente se resumem a práticas que julgo superficiais e pretendo evitar. É o que Foster descreve como «ethnographic self-fashioning» (1996, 306). São práticas nas quais o artista, muitas vezes até por encomenda de alguma instituição, por um curto espaço de tempo e geralmente dependente do financiamento, se torna pseudo-etnógrafo de comunidades nas quais se insere e pede pequenas participações. Inúmeras vezes o objeto final 
resulta num mero retrato do artista-centro-da-investigação e menoriza-se a leitura da comunidade etnográfica, em inadvertida oposição a uma séria metodologia etnográfica (Foster 1996, 307). Há, contudo, muitas exceções e seria profundamente injusto deixar a ideia de que todos os projetos colaborativos se pautam por tal ligeireza.

3. É possível aceder ao sistema Korsakow a partir do seguinte endereço eletrónico: http:// korsakow.org/. Como exemplo de um vídeo etnográfico multicanal visualize-se também: http:// planetgalata.com/korsakow/en/\#/?snu=1412

4. Como se pode ver nos seguintes endereços eletrónicos: http://vimeo.com/39284935; http:// vimeo.com/85579825, https://vimeo.com/85630130, https://vimeo.com/85874446, https:// vimeo.com/85888820.

5. Termos técnicos relativo aos movimentos de câmara. No caso de travelling o eixo da câmara desloca-se e na panorâmica a câmara move-se, mas o seu eixo não.

6. É o termo mais usado na ilha da Terceira para o texto dramático das danças de Carnaval.

\section{RESUMOS}

Neste artigo aborda-se o património cultural imaterial como performance e as suas representações em museus etnográficos como metaperformance, dando especial enfoque à necessidade do uso de imagens em movimento, segundo práticas videográficas, simultaneamente artísticas e documentais, para apresentação expositiva de conteúdos antropológicos. Inicialmente apresentase uma argumentação mais teórica sobre a importância do recurso a materiais visuais para representar elementos culturais igualmente visuais, particularmente quando se trata de linguagem não-verbal. Denotativamente, essa reflexão é aplicada no caso da exposição $O$ Carnaval é um Palco, A Ilha uma Festa, que esteve patente no Museu Nacional de Etnologia, em Lisboa, no Museu de Angra do Heroísmo e no Espaço do Conhecimento - Museu da Universidade Federal de Minas Gerais, em Belo Horizonte, Brasil. Aí são retratadas as danças de Carnaval da ilha Terceira a partir de uma videoinstalação multicanal com várias projeções.

This paper is concerned with intangible cultural heritage as performance, and its representations in ethnographic museums as metaperformance. It focuses on the need to use images in movement, following artistic-documentary video practices, as a manner of exhibiting anthropological content. Firstly, I will present theoretical arguments for the importance of using visual material in representing cultural elements that are also visual, in particular in the case of non-verbal communication. Then I will exemplify my reflection by applying it to the specific case of the exhibition The Carnival is a Stage, The Island a Feast held at the National Museum of Ethnology in Lisbon, at the Angra do Heroísmo Museum (Azores), and at the Espaço do Conhecimento Museum of the Federal University of Minas Gerais (Belo Horizonte, Brazil), in which I portrayed the Carnival Dances of the island of Terceira through a multichannel video installation with various projections.

\section{ÍNDICE}

Keywords: intangible cultural heritage, visual anthropology, exhibition

Palavras-chave: património cultural imaterial, antropologia visual, exposição 


\section{AUTOR}

\section{RUI MOURÃO}

Nasceu em Lisboa (1977). Estudou artes na Universitat Autònoma de Barcelona, Centre d'Estudis Cinematogràfics de Catalunya, Maumaus - Escola de Artes Visuais e Malmö Art Academy. Tem uma pós-graduação em Culturas Visuais Digitais do Instituto Superior de Ciências do Trabalho e da Empresa - Instituto Universitário de Lisboa e um mestrado em Antropologia no mesmo instituto. Desde 2005 expõe regularmente em Portugal e no estrangeiro. 